Disease in the Elderly

\title{
Crohn's disease of late onset in Blackpool
}

\author{
F.I. Lee and M. Giaffer
}

Department of Gastroenterology, Victoria Hospital, Whinney Heyes Road, Blackpool FY3 8NR, UK.

\begin{abstract}
Summary: Fifty five (26\%) of two hundred and fifteen patients presenting with Crohn's disease in the Blackpool area over a 15 year period (1969-1983) were over 60 years of age. There were twice as many women as men $(38: 17)$. In $60 \%$ disease was limited to the large bowel compared to only $29 \%$ in the younger age group. Many of these were women with mild distal colitis. Twenty one patients required operative management. In general, the prognosis was good in colonic disease, but in small bowel and ileocolonic disease the necessity for early operative intervention was potentially fatal. Delayed diagnosis, poor nutritional state and associated disease were relevant adverse factors. The majority of patients at the time of review were well and, where necessary, were coping satisfactorily with a stoma.
\end{abstract}

\section{Introduction}

Reports from the United Kingdom ${ }^{1,2,3,4}$ document an increasing incidence of Crohn's disease and a similar increase was suggested in Blackpool to $1980 .^{5}$ However, a more recent report suggests that a plateau occurred around 1978/79 continuing at least to $1983 .^{6}$ In the present paper we report observations in patients with Crohn's disease presenting in Blackpool for the first time after their 60th birthday between 1969 and 1983.

\section{Methods}

Previous reports ${ }^{5,6}$ have described the occurrence of new cases of Crohn's disease in the Blackpool area. The following sources were used: (a) colitis clinic records, (b) diagnostic index in the department of histopathology, (c) information from consultant colleagues at the hospital, (d) hospital activity analysis data maintained by the North West Regional Health Authority. Cases have been analysed according to age, sex and anatomical distribution, compared with those presenting before 60 years of age. The clinical course and outcome with regard to prognosis and the effects of medical and surgical management have been assessed as at December 1985.

Correspondence: F.I. Lee, F.R.C.P.

Accepted: 20 January 1987
Results

Between 1969 and 1983, two hundred and fifteen patients were recognized as presenting with Crohn's disease. Of these, $55(26 \%)$ were over the age of 60 years. The anatomical distribution in the whole series and those presenting before and after their 60th birthday is shown in Table I. In the younger age group, small bowel and mixed disease account for the majority of cases whereas in those of late onset, large bowel disease predominates, accounting for $60 \%$ of cases. There were 38 women and 17 men, a sex ratio of $1: 2.2$ compared with $1: 1.95$ for the whole series. The increased proportion of women is partly accounted for by a greater imbalance in the older age group in whom $61 \%$ were female, compared to $53 \%$ of the general population. The incidence figures show no decline with age in men ( 3.3 per $10^{5}$ for the whole series and in late onset) but a reduction in older women ( 5.7 per $10^{5}$ in the whole series compared with 4.8 per $\left.10^{5}\right)$.

Presenting features were commonly those described in series of Crohn's disease - diarrhoea, abdominal pain, weight loss and rectal bleeding. Seven presented with acute complications (3 with intestinal obstruction, 3 with perforation and 1 with massive bleeding). In 20 of 36 patients who had a barium enema colonic diverticula were present. The mean interval between onset and diagnosis was 11 months. One feature of this series relates to the high incidence of Crohn's colitis (Table II). The majority of these, particularly in women, were cases of mild distal disease (Table II). 
Table I Crohn's disease Blackpool 1969-83. Distribution of site of disease in whole series and patients presenting before and after sixtieth birthday.

\begin{tabular}{lcccc}
\hline & Whole series & $\begin{array}{c}\text { Diagnosis under } \\
60 \text { years }\end{array}$ & $\begin{array}{c}\text { Diagnosis after } \\
60 \text { years }\end{array}$ & (females) \\
\hline Large bowel & $80(37 \%)$ & $47(29 \%)$ & $33(60 \%)$ & $(22)$ \\
Mixed & $57(27 \%)$ & $46(29 \%)$ & $11(20 \%)$ & $(10)$ \\
Small bowel & $78(36 \%)$ & $67(42 \%)$ & $11(20 \%)$ & $(6)$ \\
Total & 215 & 160 & 55 & $(38)$ \\
\hline
\end{tabular}

\section{Surgical management}

Nine patients (all with extensive disease) of the 33 with large bowel Crohn's disease required surgical treatment. Four had total colectomy, three with ileostomy and one with ileorectal anastomosis. Four had hemicolectomy, three with colostomy and in one an anastomosis was carried out. One post-operative death occurred in this group. Twelve out of 22 patients with ileocolonic or small intestinal disease came to operation. Four of 9 patients died after emergency surgery and another with long strictures in the proximal jejunum and distal ileum had refused operative treatment for 2 years.

At the time of review, December 31st 1985, four patients had been lost to follow-up and one had moved from the area. Twenty six patients had died, 18 from causes not associated with Crohn's disease. In eight patients, death was directly due to Crohn's disease although associated disease was contributory in some of these. Adverse prognosis was associated with delayed diagnosis in two cases of Crohn's colitis and a combination of poor nutritional state and infection in others. Twenty four patients were available for assessment. Of these, 10 had been treated surgically and 14 had been medically managed. In all these the disease was quiescent or under control, the patients enjoying a quality of life comparable to that of their contemporaries. Three patients aged 72 years, 65 years and 80 years have an ileostomy and one aged 74 years has a colostomy. All are able to cope with a stoma life well.

Table II Large bowel Crohn's disease - 33 cases

\begin{tabular}{lccc}
\hline & Total & Extensive & Distal \\
\hline Men & 11 & 7 & 4 \\
Women & 22 & 6 & 16 \\
All & 33 & 13 & 20 \\
\hline
\end{tabular}

\section{Discussion}

In this series the proportion of patients presenting with Crohn's disease after their 60 th birthday was $26 \%$ but there is a high proportion of elderly persons in Blackpool. In Tayside $10.3 \%$ of patients presented aged 60 or over at diagnosis and $21 \%$ in Glasgow ${ }^{8}$ where the disease appeared no less common than expected in that age group. These studies were comparable to our own in that data related to defined populations. Fabricius et al..$^{9}$ commented that $8 \%$ of their Birmingham patients were over 60 at the time of diagnosis but this relates to a patient population which may include referral cases, and similar studies report late onset in $8 \%$ from Leeds ${ }^{10}$ and $5.2 \%$ from Boston. ${ }^{11}$

It is suggested that Crohn's disease in the elderly has become more common in recent years ${ }^{3}$ and this is true of Blackpool ${ }^{6}$ even allowing for the excess of women if the elderly age group. In Tayside ${ }^{7}$ it was found that sex incidence was near equal under the age of 60 but that a predominance in women occurred in the later age group. Carr \& Schofield ${ }^{12}$ also reported an excess of women in elderly patients with Crohn's disease.

A feature of the Blackpool series is that $60 \%$ of the elderly group have large bowel disease and the Glasgow workers reported exactly the same proportion. In Tayside this proportion was $50 \%$ and in the Birmingham study $45 \%$ of cases. Distal colitis accounts for a high proportion of these older patients but questions arise relating to definitions in inflammatory bowel disease. ${ }^{13,14,15}$ Cases of all age range were assessed in the same manner, but the inclusion of certain criteria, such as perianal disease and granuloma formation, as being 'diagnostic' of Crohn's disease may result in the classification of cases on inadequate or inappropriate criteria.

The occurrence of severe ileocaecal and small intestinal disease poses severe management problems. Presentation may be delayed in view of the relatively non-specific nature of the early gastrointestinal symptoms and patients may have extensive sepsis and/or obstruction and be in a poor nutritional state. The majority of deaths in this and other series follow operative management of such cases. It may be that early diagnosis ${ }^{16,17}$ and appropriate surgical resection is the treatment of choice if this can be achieved. ${ }^{12}$ 


\section{References}

1. Miller, D.S., Keighley, A.C., Langman, M.J.S. Changing patterns in epidemiology of Crohn's disease. Lancet 1974, ii: 691-693.

2. Smith, I.S., Young, S, Gillespie, G., O'Connor, J., Bell, J.R. Epidemiological aspects of Crohn's disease in Clydesdale 1961-1970. Gut 1975, 16: 62-67.

3. Mayberry, J., Rhodes, J., Hughes, L.E. Incidence of Crohn's disease in Cardiff between 1934 and 1977. Gut 1979, 20: 602-608.

4. Devlin, H.B., Datta, D. \& Dellipiani, A.W. The incidence and prevalence of inflammatory bowel disease in North Tees Health District. World J Surg 1980, 4: 183-193.

5. Lee, F.I., Costello, F.T. Crohn's disease in Blackpool incidence and prevalence 1968-1980. Gut 1985, 26: $274-$ 278.

6. Lee, F.I. \& Costello, F.T. The changing incidence of Crohn's disease in Blackpool 1969-1983. In McConnell, R.B., Rozen, P., Langman, M. \& Gilat, T. (eds) Frontiers of Gastrointestinal Research, Vol. XI. Karger, Basel, 1986, pp. 102-113.

7. Walker, M.A., Pennington, C.R. \& Pringle, R. Crohn's disease in the elderly. $\mathrm{Br}$ Med J 1985, 291: 1725 (letter).

8. Simpson, C.F., Smith, I.S. \& Young, S. Crohn's disease disease in the older patient. Gut 1986, 27 : A595.

9. Fabricius, P.J., Gyde, S.N., Shoulder, P., Keighley, M.R.B., Alexander-Williams, J. \& Allan, R.N. Cro- hn's disease in the elderly. Gut 1985, 26: $461-465$.

10. Goligher, J.C. Crohn's disease (granulomatous enteritis). In Goligher, J.C., de Dombal, F.T., Watts, J. McK. (eds) Surgery of the Anus, Rectum and Colon. 4th ed. Bailliere, Tindall, London, 1980, pp. 827-857.

11. Shapiro, P.A., Peppercorn, M.A., Antonioli, D.A., Joffe, N. \& Goldman, H. Crohn's disease in the elderly. Am J Gastroenterol 1981, 76: 132-137.

12. Carr, N. \& Schofield, P.F. Inflammatory bowel disease in the older patient. Br J Surg 1982, 69: 223-225.

13. Hywel Jones, J., Lennard-Jones, J.E., Morson, B.S. et al. Numerical taxonomy and discriminant analysis applied to non-specific colitis. $Q J$ Med 1973, 168: 715-732.

14. Holdstock, G., Savage, D., Harman, M. \& Wright, R. An investigation into the validity of the present classification of inflammatory bowel disease. $Q J \mathrm{Med} 1985$, 214: $183-190$.

15. De Dombal, F.T. The epidemiology of inflammatory bowel disease. In: de Dombal, F.T., Myren, J., Bouchier, L.A.D. \& Watkinson, G. (eds) Inflammatory Bowel Disease Oxford University Press, 1986, Oxford, pp.66-93.

16. Tchirkow, G., Lavery, I.G., Fazio, V.W. Crohn's disease in the elderly. Dis Colon Rectum 1983, 26: 177-181.

17. Foxworthy, D.M., Wilson, J.A.P. Crohn's disease in the elderly. Prolonged delay in diagnosis. J Am Geriatr Soc 1985; 492-495. 